\title{
Periodicity of Retzius lines in fossil Pongo from South China
}

\author{
HU Rong ${ }^{1,2,3}$, ZHAO LingXia ${ }^{1,2^{*}}$ \& WU XinZhi ${ }^{2}$ \\ ${ }^{1}$ Key Laboratory of Evolutionary Systematics of Vertebrates, Institute of Vertebrate Paleontology and Paleoanthropology, Chinese Academy of \\ Sciences, Beijing 100044, China; \\ ${ }^{2}$ Laboratory of Human Evolution, Institute of Vertebrate Paleontology and Paleoanthropology, Chinese Academy of Sciences, Beijing 100044, China; \\ ${ }^{3}$ Graduate University of Chinese Academy of Sciences, Beijing 100049, China
}

Received August 4, 2011; accepted October 27, 2011; published online December 2, 2011

\begin{abstract}
Periodicity of Retzius lines is a key factor in dental development. In this study, we examined the periodicity of Retzius lines in fossil Pongo from South China using polarized light microscope observation of dental ground sections. The periodicities all of the 15 teeth were $9 \mathrm{~d}$. Comparisons of periodicity were made with extant primates, fossil apes and hominins. Periodicity of fossil Pongo from South China was relatively long but fell within the variation of extant Pongo, Gorilla and modern human, and longer than periodicity of Pan and other extant primates. Fossil Pongo from South China was similar to Lufengpithecus and Sivapithecus, shorter than Gigantopithecus and longer than European and African fossil apes and most early hominins in periodicity. Generally, the periodicities of Asian large-body fossil apes were longer than the periodicities of European and African large-body fossil apes in Miocene. Difference among species and trend of evolution in periodicity were analyzed and discussed. We found that periodicity might gradually increase from Proconsul in early Miocene to several fossil apes in Miocene and then Gigantopithecus in Pleistocene. In addition, this study made correlate analysis between periodicity and body mass respectively in males and females of six extant apes and five fossil apes, and found that periodicity positively correlated with body mass.
\end{abstract}

Pongo, South China, periodicity of Retzius lines, extant apes, fossil apes

Citation: $\quad$ Hu R, Zhao L X, Wu X Z. Periodicity of Retzius lines in fossil Pongo from South China. Chin Sci Bull, 2012, 57: 790-794, doi: 10.1007/s11434011-4883-3

Incremental dental features are temporal records of development preserved in interior and on the surface of teeth and reflect the process of dental development. Studies of incremental dental development provide valued information for the reconstruction of life history and phylogeny of fossil species. Traditionally, enamel incremental features (Figure 1) include: (1) cross-striations and (2) Retzius lines and their surface manifestation, known as perikymata. Crossstriations are short-period features, of which periodicity is $24 \mathrm{~h}$. Retzius lines are referred to as long-period features because their periodicity is longer than $24 \mathrm{~h}$. Retzius lines were first found and described by Retzius in 1837 [1] and today form an important part in dental growth and development studies [2]. For example, they are a key variable for accurate estimation of the dental formation time in primates.

*Corresponding author (email: zhaolingxia@ivpp.ac.cn)
However, they can also vary between species and have different features. Retzius lines can also be used to determine the age of juveniles and to characterize individual development, providing information on taxonomy [3]. Previously studied material has included extant and fossil primates, early hominins and modern humans. In China, Zhao et al. researched dental growth and development of Lufengpithecus lufengensis and Gigantopithecus blacki [4-6]. In all the achievements of dental development, the determination of periodicity of Retzius lines is an important content, and many data have already been accumulated. But it is vacant in the dental development of Pongo from South China.

Pongo is the only great ape in Asia, living in the tropical forest of Kalimantan and Sumatra now. Fossil records [7-9] indicate that Pongo had once widely distributed in Southeast Asia and South China in Pleistocene. In most studies, fossil Pongo from South China were classified into a subspecies of 


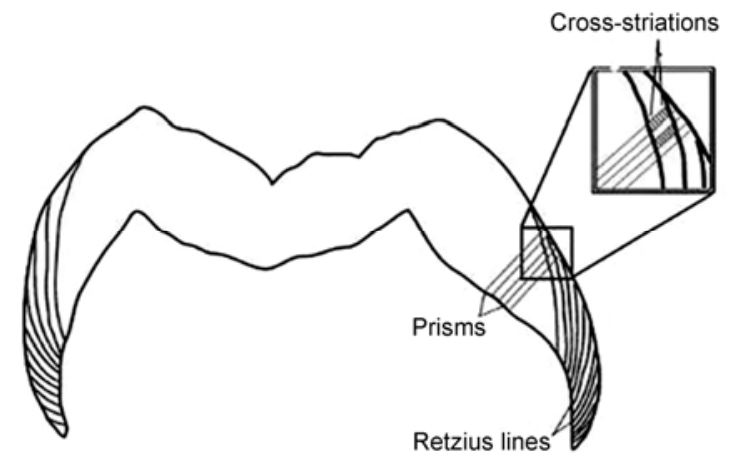

Figure 1 Molar cross-section showing incremental features and regions of the enamel microstructure [2].

Pongo pygmaeus, Pongo pygmaeus weidenreichi, to distinguish them from those of Indonesian Pongo.

In recent years, many fossil materials of Pongo have been found in South China including thousands of Pongo teeth from more than 30 sites dating from early to late Pleistocene. These fossil Pongo from South China in Pleistocene have contributed to our understanding of the evolution and classification of Asian great apes since late Miocene and the origin of early human. They are important materials for studying the origin, evolution and classification of extant Pongo. Literature concerning fossil Pongo, however, is scarce. Gu et al. [9] and Zhou [7] researched some Pongo teeth from a few sites in South China, and discussed the classification and evolution of Chinese Pongo. Wang et al. [8] discussed their classification of Pongo from South China simply based on measuring a large amount of Chinese fossil Pongo teeth and statistical analysis. Zhao et al. [10] described fossil Pongo teeth from Mulanshan cave, Chongzuo Guangxi and thought that fossil Pongo from South China was different from Indonesian Pongo. All the previous studies about fossil Pongo from South China were based on dental morphology.

In this study, we made dental ground sections of fossil Pongo from South China and observed dental incremental features under polarized light microscope to determine periodicity of Retzius lines, which provide some clues for further study of crown formation time in future, individual development and systematic taxonomy. In addition, periodicities were compared between fossil Pongo from South China with other fossil apes, early hominins, extant primate and modern human. We investigated the differences and correlations among different species of primates. Additionally, we analyzed the correlation of periodicity and body mass, which might provide some information to recover the characters of individual development of fossil hominoids and hominins.

\section{Materials and methods}

\subsection{Materials}

Fossil Pongo teeth examined in this study were obtained from Guangxi by a Guangxi field investigation team from the Institute of Vertebrate Paleontology and Paleoanthropology during the 1950s-1960s. From those samples, we selected fifteen teeth with complete crowns and with little or slight worn edges and crests. Two of those samples were from the Daxin Gigantopithecus cave, and the geological age was early Middle Pleistocene [11]. In addition, five teeth were bought from a drug store in Liuzhou. Those teeth were mainly from Laibin, Liujiang, Liuzhou, Yishan and Liucheng. Three other teeth were bought from a drug store in Nanning (Guangxi, mainly from Fusei and Chongzuo). Another five teeth were bought from drug stores in Guangxi, but the sites where they originated could not be determined. Considering that there was no Holocene material of fossil Pongo from in South China, and that the geological time of the fossil Pongo were all Pleistocene (because of associated fauns), we estimate that the date of five fossil Pongo teeth with no definite site were also of Pleistocene age.

\subsection{Production of dental ground sections}

All the teeth were cut across the mesial cusps in a buccallingual plane using an EXAKT wire saw. Procedures of making these sections are: The teeth were ultrasonically cleaned in water and etched in 5\% phosphoric acid for $20 \mathrm{~s}$. Granular DPX mounting media was paved onto the bottom of an embedded box. The teeth were put onto the DPX mounting media, and liquid DPX mounting media was then poured into the box until the teeth were submerged. The box was transferred to a light curing instrument (EXAKT 530) and exposed in blue followed by yellow light each for 6 hours. Longitudinal cuts were made using a thick wire saw (EXAKT E300CP) after which approximately 120-150 $\mu \mathrm{m}$ thick thin sections were cut using a thinner wire saw. The samples were then ground and polished to an 80-100 $\mu \mathrm{m}$ thickness using an EXAKT 400CS grinder-polisher. The sections were ultrasonicated, cleaned with ethanol, and mounted onto cover slips using DPX mounting media.

\subsection{Determination of periodicity}

Photomontages were generated with $5 \times$ and $20 \times$ objectives lenses, using a Leica polarizing light microscope and digital images were captured with a Leica DMRX camera. Retzius lines were observed firstly at 50× magnification. An area with clear cross-striations was then selected to count the number of cross-striations between successive Retzius lines, which was the periodicity of Retzius lines.

\section{Results and discussions}

Retzius lines were seen clearly in every section examined under polarized light (Figure 2). In some areas clear prism and cross-striations were observed (Figure 3 ). The periodicity 


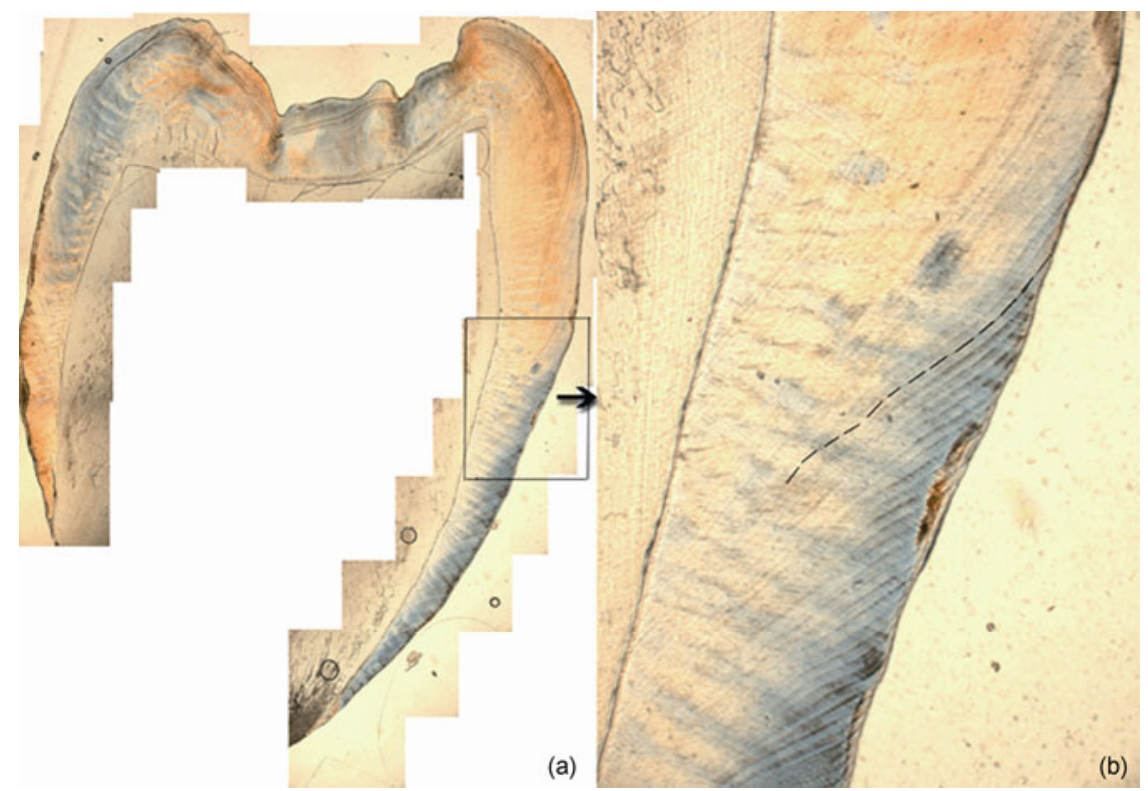

Figure 2 (a) Premolar longitudinal enamel and Retzius lines of Pongo from South China (57101-122, Table 1). The black dotted line in (b) shows a Retzius line at $50 \times$ magnification.

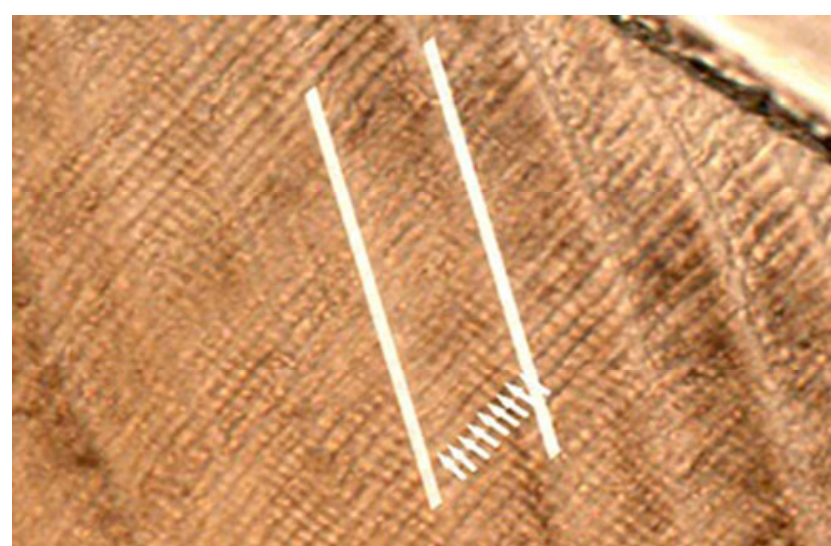

Figure 3 Retzius lines and cross-striations of Pongo from South China (LZ12, Table 1) at 200× magnification. The white straight lines are Retzius lines, and the lines of arrows show cross-striations.

obtained from all 15 fossil Pongo teeth in this study was $9 \mathrm{~d}$ (Table 1).

\subsection{Comparison with periodicity of extant primate, modern human, fossil apes and early hominins}

The periodicity of the fossil Pongo from South China is $9 \mathrm{~d}$, falling within the variations of extant Pongo and Gorilla [12], and longer than the periodicity of extant Pan, Hylobates, Symphalangus, Semnopithecus, Papio, Macaca and Malagasy. The periodicity of Pongo from South China falls within the variation of modern human and is comparable to the mean of modern human [13].

The results show that the Pongo from South China is similar to Lufengpithecus and Sivapithecus, shorter than Gigantopithecus and longer than Afropithecus turkanensis,
Ouranopithecus macedoniensis and Dryopithecus laietanus in periodicity. Periodicities of early hominins such as Australopithecus afarensis, Australopithecus africanus, Paranthropus robustus and Paranthropus robustus are mostly 6$8 \mathrm{~d}$, which is shorter than Pongo from South China. Generally, we find that the periodicities of fossil great apes in Asia were longer than those in Africa and Europe. This may be associated with radiation, spread and area isolation of great apes since the Miocene. The South China Pongo may be more closely related to Lufengpithecus, Sivapithecus, and Gigantopithecus.

In Table 2, Malagasy lemur which belongs to Prosimii

Table 1 Periodicity of fossil Pongo collected in this study from South China

\begin{tabular}{lclc}
\hline No. of specimen & Tooth type & \multicolumn{1}{c}{ Site } & Periodicity (d) \\
\hline $5657-388$ & LUM1 & Daxin Gigantopithecus cave & 9 \\
$5657-294$ & LUM3 & Daxin Gigantopithecus cave & 9 \\
$5638-155$ & LUM2 & Drug store of Liuzhou & 9 \\
$5638-305$ & RLM3 & Drug store of Liuzhou & 9 \\
$5638-240$ & RUP4 & Drug store of Liuzhou & 9 \\
LZ04 & RLM1 & Drug store in Guangxi & 9 \\
LZ12 & RLM2 & Drug store in Guangxi & 9 \\
LZ28 & LLM2 & Drug store in Guangxi & 9 \\
LZ10 & RLM3 & Drug store in Guangxi & 9 \\
LZ13 & LLM3 & Drug store in Guangxi & 9 \\
$57101-332$ & LM2 & Drug store of Liuzhou & 9 \\
$57101-122$ & LLP4 & Drug store of Liuzhou & 9 \\
$5601-128$ & RLP4 & Drug store of Nanning & 9 \\
$5601-81$ & RUP3 & Drug store of Nanning & 9 \\
$5601-100$ & RLP3 & Drug store of Nanning & 9 \\
\hline
\end{tabular}


(lower primates) has the shortest periodicity (only $3 \mathrm{~d}$ ). This is shorter than great apes, Hylobates, Symphalangus, Semnopithecus, Papio and Macaca which belong to Anthropoidea (higher primates). The periodicities of great apes (Pongo, Pan and Gorilla) are longer than those of small apes (Hylobate and Symphalangus). The periodicities of Macaca and Papio (Cercopithecinae) are longer than those of Semnopithecus (Colobinae). Additionally, the periodicities of fossil apes with different geological ages were compared. We found that periodicity might gradually increase from Proconsul in early Miocene to several fossil apes in Miocene and then Gigantopithecus in Pleistocene. The periodicity of modern human has a large range of variation. Its maximum $(12 \mathrm{~d})$ is much longer than the periodicity of Austalopithecus $(6-8 \mathrm{~d})$.

Table 2 Periodicity of Retzius lines in extant primates, fossil apes and early hominins

\begin{tabular}{|c|c|c|}
\hline Taxon & $n$ & Periodicity (d) \\
\hline \multicolumn{3}{|l|}{ Extant } \\
\hline Modern human [12] & 678 & $6-12$ \\
\hline Pan troglogytes [1] & 135 & $6-7$ \\
\hline Pan troglogytes $[14]$ & 4 & $7-8$ \\
\hline Pan paniscus [1] & 2 & $6-7$ \\
\hline Pongo pygmaeus [13] & 24 & $8-11$ \\
\hline Gorilla gorilla [13] & 36 & $7-10$ \\
\hline Hylobates lar [15] & 3 & 4 \\
\hline Symphalangus syndactylus [15] & 3 & 5 \\
\hline Semnopithecus entellus priam [15] & 1 & 5 \\
\hline Papio hamadryas [15] & 1 & 7 \\
\hline Macaca nemestrina [16] & 98 & 8 \\
\hline Malagasy lemur [17] & 2 & 3 \\
\hline \multicolumn{3}{|l|}{ Fossil } \\
\hline Proconsul heseloni [18] & 2 & 5 \\
\hline Proconsul nyanzae [18] & 2 & 6 \\
\hline Afropithecus turkanensis [19] & 2 & $7-8$ \\
\hline Ouranopithecus macedoniensis [20] & 1 & 8 \\
\hline Dryopithecus laietanus [21] & 3 & $6-7$ \\
\hline Sivapithecus parvada [22] & 1 & 9 \\
\hline Sivapithecus induicus [22] & 1 & 8 \\
\hline Lufengpithecus hudienensis [23] & 2 & 7 \\
\hline Lufengpithecus hudienensis [23] & 1 & 9 \\
\hline Lufengpithecus lufengensis [4] & 2 & 9 \\
\hline Pongo sp. (present study) & 15 & 9 \\
\hline Gigantopithecus blacki [24] & 1 & 11 \\
\hline Australopithecus afarensis [25] & 3 & 7 \\
\hline Australopithecus africanus [26] & 8 & $6-8$ \\
\hline Paranthropus robustus[26] & 7 & $6-8$ \\
\hline Paranthropus robustus [27] & 1 & 9 \\
\hline Paranthropus boisei [28] & 1 & 7 \\
\hline Homo neanderthalensis [29] & 1 & 7 \\
\hline
\end{tabular}

\subsection{Correlation analysis of periodicity and body mass in living primates and early hominins}

Life history traits are a combination of interrelated events, including the timing of key maturational events such as weaning, menarche, age at first reproduction, adult brain size, body mass and longevity. Dental development closely correlates with an individual's life history, and periodicity is an important variable in dental development. Reid et al. [30] reported a positive correlation between periodicity and body mass in hominoids, but did not discriminate between genders. In this study, we analyzed the correlation between periodicity and body mass in six extant apes (Pan troglogytes, Pan paniscus, Pongo pygmaeus, Gorilla gorilla, Hylobates lar and Symphalangus syndactylus) and five fossil apes (Australopithecus afarensis, Australopithecus africanus, Paranthropus robustus, Paranthropus boisei and Homo neanderthalensis). Considering gender difference of body mass, we analyzed males and females separately. Body mass data was taken from the Fleagle [31]. Where a range of periodicity was given, we used the median value. Our results show that periodicity positively correlates with adult body mass (Figure 4). The correlation coefficient for females is $0.615(P<0.05)$ and for males is $0.748(P<0.01)$ (Table 3). It is inferred that body mass and life history of fossil Pongo from South China might be in the variation of extant Pongo.

\section{Conclusions}

To summarize, the periodicity of Retzius lines of fossil Pongo from South China is relatively long, when compared to extant primates, fossil apes and early hominins. Periodicity is significantly positively correlated with body mass. It seems that Pongo, Lufengpithecus and Gigantopithecus hominoids from Asia have longer periodicity compared with Miocene fossil apes in Europe and Africa, which have some referenced values to analyze classification, evolution and adaptation of hominoids in different times and areas.

Table 3 Periodicity and body mass in living primates and early hominins

\begin{tabular}{lccc}
\hline \multirow{2}{*}{ Taxon } & \multirow{2}{*}{ Periodicity (d) } & \multicolumn{2}{c}{ Body mass [31] (kg) } \\
\cline { 3 - 4 } & & Female & Male \\
\hline Pan troglogytes & $6-7$ & 45.8 & 59.7 \\
Pan paniscus & $6-7$ & 33.2 & 45.0 \\
Pongo pygmaeus & $8-11$ & 35.6 & 77.9 \\
Gorilla gorilla & $7-10$ & 97.5 & 162.5 \\
Hylobates lar & 4 & 5.34 & 5.9 \\
Symphalangus syndactylus & 5 & 10.7 & 11.9 \\
Australopithecus afarensis & 7 & 29.3 & 44.6 \\
Australopithecus africanus & $6-8$ & 30.2 & 40.8 \\
Paranthropus robustus & $6-8$ & 31.9 & 40.2 \\
Paranthropus boisei & 7 & 34 & 48.6 \\
Homo neanderthalensis & 7 & 76 & 76 \\
\hline
\end{tabular}




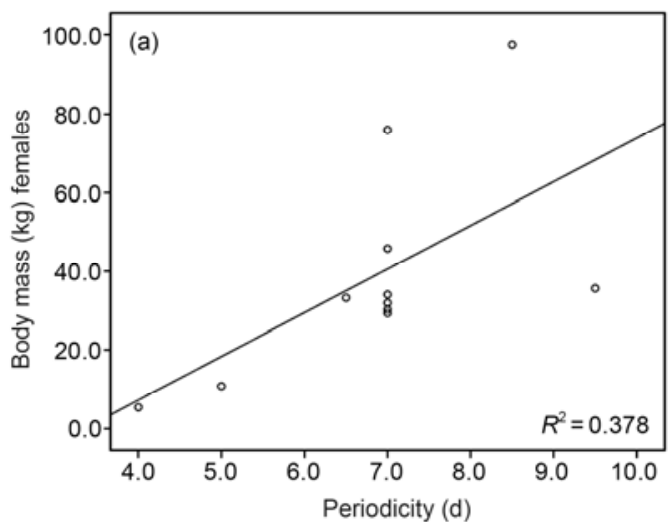

Figure 4 Correlation of periodicity and body mass in extant and fossil apes.

This work was supported by the Open Foundation of State Key Laboratory of Palaeobiology and Stratigraphy (103105), the National Natural Science Foundation of China (41072016) and the National Basic Research Program of China (2007FY110200).

1 Smith T M. Incremental development of primate dental enamel. Dissertation for the Doctoral Degree. New York: Stony Brook University, 2004

2 Smith T M, Martin L B, Leakey M G. Enamel thickness, microstrucutre and development in Afropithecus turkanensis. J Hum Evol, 2003, 44: $286-306$

3 Bromage T G, Dean M C. Re-evaluation of the age at death of immature fossil hominids. Nature, 1985, 317: 525-527

4 Zhao L X, Lu Q W, Xu Q H. Enamel microstructure of Lufengpithecus lufengensis. Acta Anthrop Sin, 2000, 19(Suppl): 77-108

5 Zhao L X, Zheng L, Gao F, et al. Preliminary study on enamel microstructure of Yuanmou Miocene hominoids of China. Sci China Ser D-Earth Sci, 2002, 32: 921-927

6 Zhao L X. Comprehensive dental study on Gigangpithecus blacki (in Chinese). Dissertation for the Doctoral Degree. Beijing: Graduate University of Chinese Academy of Sciences, 2006

7 Zhou G X. The distribution and evolution of Pongo in South China (in Chinese). Mem Beijing Nat Hist Mus, 2002, 60: 71-87

8 Wang C B, Zhao L X, Jin C Z, et al. A comparative study on the tooth crown size of Pleistocene fossil orangutan from South China and its taxonomic implication (in Chinese). Acta Anthropol Sin, 2009, 28: $192-200$

9 Gu Y M, Huang W B, Song F Y, et al. The study of some fossil Orang-Utan teeth from Guangdong and Guangxi. Acta Anthropol Sin, 1987, 6: 272-283

10 Zhao L X, Wang C B, Jin C Z, et al. Fossil Orangutan-like hominoid teeth from Late Pleistocene human site of Mulanshan cave in Chongzuo of Guangxi and implications on taxonomy and evolution of orangutan. Chin Sci Bull, 2009, 54: 3924-3930

11 Han D F. Mammalian fossils from Tahsin County, Guangxi (in Chinese). Vert Palas, 1982, 20: 59-64

12 Schwartz G T, Reid D J, Dean C. Developmental aspects of sexual dimorphism in hominoid canines. Int J Primatol, 2001, 22: 837-860

13 Reid D J, Dean M C. Variation in modern human enamel formation times. J Hum Evol, 2006, 50: 329-346

14 Reid D J, Schwartz G T, Dean C, et al. A histological reconstruction of dental development in the common chimpanzee, Pan troglodytes. $\mathrm{J}$ Hum Evol, 1998, 35: 427-448

15 Dirks W, Bowman J E. Life history theory and dental development in four species of catarrhine primates. J Hum Evol, 2007, 53: 309-320

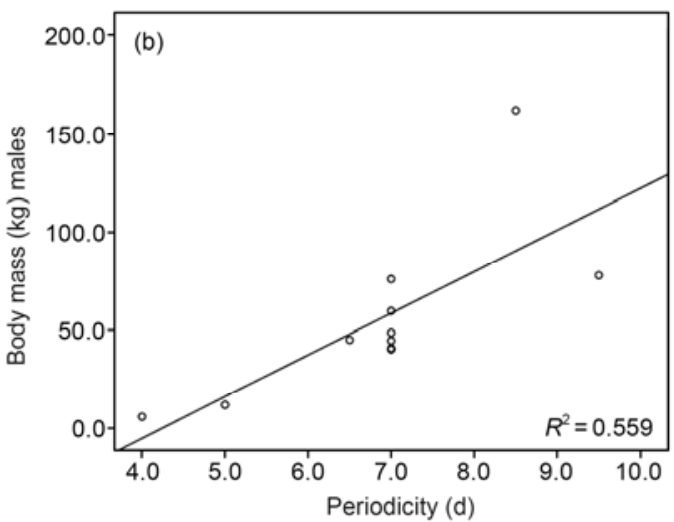

16 Smith T M. Experimental determination of the periodicity of incremental features in enamel. J Anat, 2006, 208: 99-113

17 Schwartz G T, Godfrey L R, Mahoney P. Inferring primate growth, development and life history from dental microstructure: The case of the extinct Malagasy lemur, Megaladapis. In: Bailey S E, Hublin J J, eds. Dental Perspectives on Human Evolution. Dordrecht: Springer, 2007. 147-162

18 Beynon A D, Dean M C, Leakey M G, et al. Comparative dental development and microstructure of Proconsul teeth from Rusinga Island, Kenya. J Hum Evol, 1998, 35: 163-209

19 Kelley J, Smith T M. Age at first molar emergence in early Miocene Afropithecus turkanensis and life-history evolution in the Hominoidea. J Hum Evol, 2003, 44: 307-329

20 Smith T M, Martin L B, Reid D J, et al. An examination of dental development in Graecopithecus freybergi (=Ouranopithecus macedoniensis). J Hum Evol, 2004, 46: 551-577

21 Kelley J, Dean M C, Reid D J. Molar growth in the late Miocene hominoid, Dryopithecus laietanus. In: Brook A, ed. Dental Morphology 2001: 12th International Symposium on Dental Morphology. Sheffield: Sheffield Academic Press, 2001. 123-134

22 Mahoney P, Smith T M, Schwartz G T, et al. Molar crown formation in the Late Miocene Asian hominoids, Sivapithecus parvada and Sivapithecus indicus. J Hum Evol, 2007, 53: 61-68

23 Schwartz G T, Liu W, Zheng L. Preliminary investigation of dental microstructure in the Yuanmou hominoid (Lufengpithecus hudienensis), Yunnan Province, China. J Hum Evol, 2003, 44: 189-202

24 Dean M C, Schrenk F. Enamel thickness and development in a third permanent molar of Gigantopithecus blacki. J Hum Evol, 2003, 45: 381-387

25 Lacruz R S, Ramirez-Rozzi F V. Molar crown development in Australopithecus afarensis. J Hum Evol, 2010, 58: 201-206

26 Lacruz R S, Ramirez-Rozzi F V, Bromage T G. Variation in enamel development of South African fossil hominids. J Hum Evol, 2006, 51: 580-590

27 Dean M C. Daily rates of dentine formation in macaque tooth roots. Int J Osteoarchaeol, 1993, 3: 199-206

28 Dean M C. Growth layers and incremental markings in hard tissues: A review of the literature and some preliminary observations about enamel structure in Paranthropus boisei. J Hum Evol, 1987, 16: 157-172

29 Smith T M, Harvati K, Olejniczak A J, et al. Brief communication: Dental development and enamel thickness in the Lakonis Neanderthal Molar. Am J Phys Anthropol, 2009, 138: 112-118

30 Reid D J, Ferrell R, Walton P. Histological of dental derived canine crown formation times from a medieval Danish sample. Am J Phys Anthrop, 2002, 34(Suppl): 129

31 Fleagle J G. Primate Adaptation and Evolution. 2nd ed. San Diego: Academic Press, 1999

Open Access This article is distributed under the terms of the Creative Commons Attribution License which permits any use, distribution, and reproduction in any medium, provided the original author(s) and source are credited. 